\title{
TODO DIA É VINTE E CINGO DE JANEIRO
}

\section{André Luiz Freitas Dias}

Fernando Antônio de Mélo

Cordel é poesia do povo

Que sabe captar sentimentos

Sejam fatos da história

Sejam amores, tormentos

Nesse caso ele registra

Com poesia os sofrimentos

Mais aprendemos com o tempo

Conhecer nosso lugar

Quem sabe da dor do povo

É quem por ela passar

Queremos só com estes versos

Tristeza compartilhar

Nossa história em Brumadinho

É anterior ao crime

Foi na luta pela água

Que a Coca-Cola suprime

Lá da Serra da Moeda

Que sem água, ao povo oprime

Foram tantas violências

Violaçōes de direitos e danos

Que o Polos foi convocado

Para enfrentar os Tiranos

A Vale e os governos

Buscando lucros insanos

E com a comunidade

A verdade revelar

Pois junto com o sofrimento

Vem a força de lutar

Lutar contra covardias

$\mathrm{E}$ a frieza de matar

Mas o povo é sempre esperto

Com as mentiras amáveis

Que tornam crimes graves

Em fatos inevitáveis

E a Jóia brasileira

com desculpas inesgotáveis
Do Espetáculo do Desastre

Negamos participar

Os protagonismos locais

Queremos valorizar

A voz do povo é quem manda

Só vamos amplificar

É outro nosso compromisso

Universidade que mobiliza

Fortalece políticas públicas

Que o direito preconiza

Junto à saúde local

Que os cuidados realiza

Com este cordel queremos

Nosso respeito expressar

Duzentas e setenta e duas vidas

A ganância veio ceifar

Que nunca serão esquecidas

Nem a história vai apagar

Por isso nos coraçōes

De Brumadinho inteiro

Dilacerados com a dor

Desse crime sorrateiro

Todo dia que amanhece

É Vinte e Cinco de Janeiro

\section{CORPOS DESCARTÁVEIS}

Um esquete do Programa Transdisciplinar Polos de Cidadania da UFMG

Dramaturgia: Fernando Limoeiro e trupe

"A torto e a direito"

Direção: Fernando Limoeiro

Trupe "A torto e a direito": Sol Markes Santos, Jéssica Naiane Cordeiro Alcântara, Marco Antônio Rodrigues de Aguiar Júnior, Raquel de Faria Rodrigues, Alice de Oliveira Cabral e Silva, Lucas Raimundo
Pesquisadores-extensionistas envolvidos: André Luiz Freitas Dias e Gabriel Augusto Vilaça da Silveira

PRÓLOGO: Num espaço público ou praça de uma comunidade, uma trupe de teatro se apresenta, abordando uma catástrofe criminosa que acabara de acontecer e atingiu a todos os moradores.

PERSONAGENS (por ordem de entrada):

Arauto - narrador

Valéria Ganancia - Morte

Conceição Brumadinho - defunta agricultora que ajudava o tio na lavoura às margens do Paraopeba

Eustáquio Brumadinho - defunto motorista; funcionário terceirizado

Alberto Brumadinho - defunto engenheiro da Cale

Arauto: Vamos se aproximando, senhoras e senhores, que a trupe "A torto e a direito", do Programa Polos de Cidadania, junto com o Teatro Universitário da UFMG, preparou um espetáculo exclusivamente para vocês! Vocês que querem se divertir e, ao mesmo tempo, refletir, prestem atenção a esse emocionante, lacrimejante e estonteante esquete teatral. Vale ressaltar o quanto a arte é necessária ao homem e não adianta censurar ou cortar verba, porque teatro verdadeiro é aquele feito de sonho e de garra, que ensina divertindo e diverte educando! Alegra os justos e aos injustos vai incomodando. Com vocês: Corpos Descartáveis!

\section{Em7 A7 B7 Em7}

Sob o sol quente do dia

No roçado ou na caldeira

Pro povo da nossa terra

É sempre segunda-feira

Uma empresa de renome

Conhecida e respeitada

Fazia do dia a dia

Desse povo uma empreitada 
Refrão

É garimpeiro, motorista, engenheiro

Todo mundo contratado

Trabalhando com minério

Mas a empresa esqueceu de avisar

Que dinheiro na verdade

É o que era levado a sério

Eustáquio:

Trabalhava a qualquer hora

Sem saber como voltar

Duas horas da manhã

Me faziam acordar

Sem saber sequer meu nome

O chefão mandou chamar

Dirigir sei lá pra onde

Só me resta trabalhar

Refrão

É garimpeiro, motorista, engenheiro

Todo mundo contratado

Trabalhando com minério

Mas a empresa esqueceu de avisar

Que dinheiro na verdade

É o que era levado a sério

Alberto:

A camisa da empresa

Eu vesti sem questionar

Emprego de engenheiro

Tenho que valorizar

Bate ponto, faz visita

Vivo no computador

Toda hora é reunião

Nunca desliga o motor
Refrão

É garimpeiro, motorista, engenheiro

Todo mundo contratado

Trabalhando com minério

Mas a empresa esqueceu de avisar

Que dinheiro na verdade

É o que era levado a sério

Conceição:

"Isso é coisa do trem ruim"

Foi meu tio que me disse

As plantas quase morrendo

Olha só que esquisitice

O meu rio Paraopeba

Já não dá mais alimento

Essa empresa só enriquece

E a gente sem sustento

Arauto

Essa gente na labuta

Seguia seu dia a dia

Trabalhando a mil por hora

Mas mantendo a alegria

Porque além de trabalho,

Tinha família e escola,

Tinha casa, tinha sonho

Correndo cidade afora

Tinha também uma barragem

Construída na cidade

A partir dela, sustento

Pra essa gente sem maldade

E foi justo essa barragem

Por descaso da empresa

Que provocou triste fim

Chegado em tom de surpresa

Surpresa nem sempre é boa

E essa nos fez chorar

Sem preparar as pessoas

Pro alarme que ia tocar
Não deu tempo de ir embora

De largar sua cidade

Que virou leito de lama

Grande palco da maldade

Foi-se embora muita gente

Ficaram só na memória

E a empresa imoral

Marcou com lama a história

Adeus povo bom, adeus

Adeus aos que foram embora

Adeus povo bom, adeus

Adeus aos que foram embora!

(Arauto, junto com a Morte, entra marcando com um tambor numa espécie de cortejo fúnebre, enquanto os atores defuntos respondem em coro)

Primeira Incelênça (cantado):

\section{G C D}

Uma incelênça

Pra quem está na lama

Despertem, não se esqueçam

Que os mortos reclamam

(Eustáquio-falado)

Despertem, nunca esqueçam

Que os mortos também reclamam

Duas incelenças

Pra não ter confusão

Esse mar é rejeito

De contaminação (bis - Conceição)

Três incelênças

Dizendo que a hora é hora

É a sina de Minas

Destroem e vão embora

(Alberto-falado)

É a sina de Minas

Destroem, faturam e vão embora 
Arauto (em tom de contador de história):

Num espaço encantado

Onde as palavras têm rimas

Onde as coisas mais terríveis

Se transformam em coisas lindas

Acontecem mil histórias

Que nos tocam, são bem vindas

Bem vindas para esclarecer

Os labirintos da história

Dos crimes que muitas vezes

São contados como glória

Principalmente pra gente

De alma boa e simplória

Um poeta se rebelou

E abandonou a cidade

Pelos estragos que uma firma

Causou na comunidade

Destruindo um morro inteiro

Por ganância e crueldade

E deixou esse cordel

Contando revolta e sina

Dos sonhos que destruíram

Atacando na surdina

E o poeta, junto ao povo

Protesta com duras rimas

Morte:

Eu sou Valéria Ganância

Permitam me apresentar!

Já que ele falou meu nome

É hora de eu me expressar

Essa história mal contada

Tenho que recontar

Uma empresa chamada Cale

Que trouxe emprego e progresso

Arriscou muito dinheiro

Construindo seu sucesso

Sofreu acidente grave

Destruindo seu processo

Processo que sempre trouxe

Ao povo benfeitorias
Mudando toda a cidade

Ampliando a economia

A cultura e a educação

Numa total melhoria

Porque na verdade a Cale

É uma joia brasileira

E não pode ser culpada

Por uma simples besteira

Que faz esse povo ingrato

Esquecer a história inteira

Conceição: (levanta-se) Epa! Agora foi demais! Era só o que faltava, aparecer essa figura, manequim de cemitério, pra defender um crime! E mesmo depois de mortos somos chamados de ingratos. Imaginem quem tá vivo, o que não tem que aguentar... Fico pensando nas comunidades ribeirinhas, que, como meu tio, a vida inteira dependeram da água pra plantar, pra comer, pra viver. Eles acham que o dinheiro compra tudo!

Eustáquio: (levanta-se) E compra mesmo! Epa digo eu! Pois, na verdade, Conceição, até pra ser defunto carece de ter sorte. Eu já soube que um morto como eu, terceirizado, vale bem menos do que um defunto contratado pela Cale. Minha família vai se lascar!

Alberto: (levanta-se) Eustáquio, inveja depois de morto não vale nada. De que adianta se o dinheiro que eu vou receber como funcionário da Cale não poderei desfrutar?

Eustáquio: Mas já desfrutou. E muito! Além da estabilidade de emprego, que eu nem cheguei perto, Alberto. E depois, tudo que acontece de errado, a culpa é do terceirizado!

Alberto: Ah, mas tem coisas que dinheiro não paga. Ou você acha que a nossa vida tem preço?
Eustáquio: É claro que para a Cale a nossa vida vale muito pouco! Agora, quanto ao dinheiro, Alberto, sua família vai estar muito mais bem assistida, é ou não é? Só o seu plano de saúde é maior que meu salário!

Conceição: Eustáquio Brumadinho e Alberto Brumadinho! Vocês parem com essa discussão que a Cale adora jogar uns contra os outros e ficar assistindo. Quanto mais intriga houver, menos articulação vai ter.

Eustáquio: É isso mesmo, Conceição! Nós não podemos mais cair nessa armadilha. Principalmente depois de morto. Se a gente nunca brigou em vida nem por causa de dinheiro, porque vai brigar agora na morte?

\section{C\#m F\#m Gm}

Olha só, veja só

Não precisa de mais conflito

Só vai deixar mais aflito

Olha só, vamos ver

Se a gente trabalhar juntos

É mais fácil resolver

É... tanta coisa

Que eu perdi minha razão

Não adianta brigar

Pra encontrar solução (bis)

(todos concordam)

Alberto: É isso mesmo! Para a Cale, é fácil resolver tudo com dinheiro. Mas a dor que a minha família está sentindo não tem preço. Eles nunca vão nos esquecer! Os mortos costumam ficar mais vivos na memória dos que ficam.

Conceição: Acredita que eu não tinha pensado nisso, Alberto? Às vezes, os vivos estão mais mortos do que nós. E todo lugar que tinha cheiro de lembrança agora 
tem cor de saudade, de lama, de perda. Eu fico pensando na agonia de minha família quando chegou a notícia do rompimento. Já são 8 dias de espera e ninguém encontra nossos corpos.

Eustáquio: E minha mãe, então? Ser filho único é dor dobrada. Parece que eu estou vendo ela ajoelhada nos pés de Nossa Senhora Aparecida, rezando dia e noite.

\section{(Arauto entra)}

Arauto:

Entre os crimes mais terríveis

Mais cortantes e medonhos

O pior deles, acredite

É poder matar os sonhos

Porém os sonhos resistem

Com a força da esperança

Em cada flor que renasce

Em cada nova criança

(Arauto canta junto aos mortos e a plateia: Amo-te muito - Nara Leão)

Amo-te muito

Como as flores amam

O frio orvalho que, infinito, chora

Amo-te como o sabiá da praia

Ama a sanguínea

E deslumbrante aurora

Ó não te esqueças

Que eu te amo assim

Ó não te esqueças

Nunca mais de mim

Eustáquio: É... E o pior: a Cale calou-se diante da nossa dor. Trata todo esse sofrimento como se fosse um dado estatístico, um acidente de percurso... Até as noites mudaram. Papo de boteco agora sempre termina em papo de morte. Ninguém faz mais seresta, ninguém conta mais piada... no meio da conversa sobre futebol, entra o rompimento da barragem.
Alberto: Todos só querem falar da dor da perda e dessa melancolia que tomou conta de tudo, mas apesar disso, a cidade resiste!

Conceição: Verdade, Alberto! E eu tenho certeza que nosso povo está lutando e vai continuar nessa batalha até que toda a cidade se regenere. Eu sempre acredito numa nova primavera.

Eustáquio: Eu sou otimista até depois de morto.

Conceição/Alberto (rindo): Otimista? Você?

Alberto: Tudo que você fez desde que a gente chegou aqui foi reclamar!

Eustáquio: Que isso, também não é assim não! Tô falando sério! Eu acho que eles estão muito perto de nos encontrar.

Alberto: Olha, otimista eu também sou, mas em tempos de meias verdades, é bom lembrar que esse país tem memória curta.

Eustáquio: Já estão quase esquecendo da catástrofe de Mariana que não faz nem cinco anos! Porque aqui nesse país um escândalo cobre o outro, uma dor sufoca a outra, essa é que é a verdade!

Morte: (voltando, junto ao Arauto, que acompanha os versos, marcando com o bumbo) Falou em verdade, é comigo mesmo! Olha aqui, se dependesse de mim, já tinha encontrado vocês todos e eu já estaria longe daqui.

\section{Em A9}

Eu sou a rainha do nada

Dama do absoluto

Seja dono ou empregado

Seja dia ou no escuro

Quando beijo meus amados

Claro que eu faço carícias de luto
Defuntos:

\section{Em A9}

Não queremos carícias

Nem seus beijos de morte

Você se exaltando

Por ceifar nossa sorte

Todo esse sofrimento

Pra você não passa de esporte

Morte: $\mathrm{O}$ quê? Se vocês pensam que eu gosto desse tipo de morte, estão muito enganados. Não tem grife, nem exclusividade.

Eustáquio: Grife? Um horror desses e você pensando em exclusividade? Você não faz ideia do tamanho da dor que essas mortes causaram!

Alberto: Não sabe! Não tem ideia da dor que eu tive por não poder entregar o primeiro presente para o meu filho que ia nascer.

Morte: Eu não tenho nada a ver com nascimento! Isso é uma falta de respeito com meu ofício eterno!

\section{D\#m7 A\#7 | A\#7 G\#m D\#m7}

Eu detesto batizados

Gosto de velórios grandes

Crematórios com direito

A buffet e espumantes

E também com vinhos raros

Coroas com orquídeas grandes

$\mathrm{Ou}$ as mortes nordestinas

Com cançôes emocionantes

Carpideiras com inselências

Lágrimas cristalizantes

Conceição: Você gosta e acha bonito porque não sabe de nada! $\mathrm{O}$ meu tio foi achado e foi velado num caixão trocado. A mulher dele já tinha derramado um riacho de lágrimas quando chegou a fu- 
nerária e falou: "Ó, eu sinto muito, mas o seu defunto é outro, viu?”. Já pensou? Chorar pelo defunto errado?!

Eustáquio: Misericórdia! Se fosse comigo eu gritava com todo tudo mundo até abrirem o caixão pra eu ter certeza de quem tava lá!

Conceição: E ela gritou! A Cale não deixou: “caixão aqui é lacrado!" Ela fez um escândalo de dor. Adiantou? Como os velórios só podiam durar de 5 a 15 minutos, a Cale mandou vir um enfermeiro e aplicou um sossega-leão nela.

Morte: Estratégia, meu bem. Estratégia! Todo velório se presta à comoção e pobre adora um escândalo! Já imaginaram aquele povo todo revoltado contra a Cale e berrando em todos os caixões? Ia ser uma loucura! Nenhuma empresa suporta tanta propaganda negativa, mesmo sendo uma joia para a economia. Mas vamos mudar de assunto...

Alberto: Mudar nada, eu tô reconhecendo essa sua voz venenosa...

Conceição: Eu também!

Eustáquio: Eu mais ainda!

Alberto: Eu lembro de ter lhe visto num escritório da Cale recebendo um malote. Era o preço pago por nós, não era? Não é a toa que você se chama Valéria Ganância.

Morte: É que pra mim só há um poder que pode enfrentar a morte. Só há uma força para a qual eu me rendo. Nada é mais forte pra mim do que o dinheiro.

\section{G C D G}

Dinheiro não perde guerra

Para tudo é solução

Manda em tudo nessa terra

Paga até minha missão
E pra quem aí disser

Que eu não tenho razão

Procure se informar

Mude sua opinião

Dinheiro não perde guerra

Para tudo é solução

Manda em tudo nessa terra

Paga até minha missão

Pode até calar o povo

E mudar opiniāo

Dinheiro é coisa boa

(Apenas a morte) Aquece meu coração

Morte: Tenha dinheiro e tudo o mais lhe virá como acréscimo!

Eustáquio: Eu fico pensando na hora em que começarem esses pagamentos.

Morte: Vocês ainda irão ver o jogo virar. E essa mala vai provar (abre a mala com dinheiro). Às vezes, o dinheiro faz até a lágrima secar.

Alberto: E a ganância faz ela desaparecer. Eu aposto que essa é a famosa mala dos 700 mil.

Morte: E se for? Não é da sua conta!

Conceição: Mas é da minha! Garanto que minha família nunca vai esquecer da dor dessa tragédia. Gente como eu nasceu e criou-se na terra, o adubo do coração é outro. Suborno é erva daninha, é carrapixo que garra na alma!

Morte: Fofa, você esquece que meu ofício merece ser bem remunerado, porque sou a única que pode exercê-lo. E toda exclusividade tem seu preço. (em tom de provocação) Eu só não entendo por que vocês facilitaram tanto o meu serviço...

Eustáquio: Ah, mas é agora que eu mato essa Morte! A culpa é nossa? A responsável por isso tudo é a Cale! Inclusive, pelo restaurante para os funcionários, que estava cheio de gente almoçando na hora que a lama chegou.

Conceição: E quer saber mais? Muita coisa já estava aqui antes da Cale chegar. Por isso, os velhos moradores, como meu tio, ficaram arrasados, indignados, e com toda razão! A lama enterrou nossa história.

Todos (exceto Conceição): É o preço pago pela minerodependência.

Conceição: Minero o quê?

Eustáquio: Mi-ne-ro-de-pen-dên-ci-a! As mineradoras chegam com seu poder financeiro e dominam a comunidade. Tem gente que é até contra a gente ser contra.

Alberto: Emprego pra uns...

Conceição: Indenização pra outros...

Alberto: Lazer para todos! Basta ver os bailes, as festas... Chamaram até Simone \& Simária para cantar aqui... Até um boulevard eles fizeram em Barra Longa, querendo provar o "desejo de restauração da natureza”.

Morte:

\section{A E A D}

Todo mundo saiu ganhando tudo novo e brilhante onde tem festa pro povo tem sorriso estonteante

A natureza restaurada agora tá tudo bem a cidade tá alegre reunida em paz e bem

Alberto: O famoso pão e circo né! Ah, por favor! 
Eustáquio: Mais essa pra gente engolir, eu hein!

Arauto:

$$
\begin{aligned}
& \text { Mas essa restauração } \\
& \text { Não deu grande resultado } \\
& \text { O boulevard na verdade } \\
& \text { Era todo maquiado } \\
& \text { A intenção verdadeira } \\
& \text { Era cobrir o estrago } \\
& \text { Pintaram a grama seca } \\
& \text { Com o verde mais destacado } \\
& \text { E de branco os coqueiros } \\
& \text { Em que a lama tinha grudado } \\
& \text { E o povo olhando de longe } \\
& \text { Até que achou ajeitado } \\
& \text { Mas não contavam com os cães } \\
& \text { Rolando em grama pintada } \\
& \text { Ficando assim todos verdes } \\
& \text { A farsa desmascarada } \\
& \text { Provando que a cidade } \\
& \text { Em nada foi restaurada }
\end{aligned}
$$

Eustáquio: Enquanto isso, a terra vai sendo corroída e arrasada. E o minério extraído vai sendo beneficiado e reaproveitado para enriquecer o bolso deles. Isso sem falar que as águas de minas estão todas comprometidas com a mineração.

Conceição: Pelo que eu tô vendo, os nossos lençóis d'água tão servindo é para cobrir as falcatruas da Cale.

Alberto: Eu não acredito que eles ainda conseguem lucrar com essa tragédia em forma de lama.

Eustáquio: Pois lucram! Eles estão garimpando e faturando com o minério que retiram do rejeito! E pra gente, o que é que sobra?

Morte: Sobra o bem-estar e o progresso, seus ingratos! $\mathrm{O}$ que era essa cidade antes da Cale chegar? Uma cidadezinha qualquer do interior de Minas...

Conceição: Nada disso! Era um povo sossegado, vivendo na sua terra, do que plantavam, do que colhiam. Todo mundo em paz.

Arauto: Me lembrei do poeta, que disse: "cada um de nós tem seu pedaço no pico do Cauê”. Agora, essa cidade é só uma fotografia na parede.

Todos os defuntos: Mas como dói..

Morte: Pera aí... eu acho que eu tô ficando doida. O que que eu tô fazendo aqui? Conversando com defuntos, casos já resolvidos... Isso só pode ser teatro!

\section{Em A9 B7}

Ô povinho enxerido

Esquisito e danado

Está sempre do contra

Nunca fica calado

E cutuca a história inteira até encontrar

O que é falso e errado!

Mortos:

Só você não enxerga
Que o jogo virou
Você não acredita
A história acabou
Tira essa máscara que por tanto tempo
Lhe cegou

Morte: Cheeeeega! Tá bom, eu já entendi! (pausa. Atriz percebe que está fazendo teatro)

Tuuuuuum! (os mortos congelam)

Arauto:

Acontece, meu grande povo

Que isso tudo é teatro

A gente faz fantasia

Pra olhar melhor o fato
Essa morte que vos fala

Desde o início tão cruel

Sem limites, nem rigor

É atriz no seu papel

Mas ninguém quer terminar

A peça com tanta dor

Então minha querida morte

Se despeça, por favor

Morte: (tirando o chapéu)

Um espetáculo pra ser justo

Também pode utilizar

Uma personagem cruel

Servindo pra reforçar

Que a verdade disso tudo

É que nada foi acidente

Porque tem nome o culpado

E também tem precedente

Mas a morte já fez sua parte

Veio pra representar

Os verdadeiros criminosos

Que ainda tentam se ausentar

Me despeço da personagem

E me mostro como artista

Eu, através do teatro

Espero que você reflita

Peço perdão a todos

E agradeço pela acolhida

Não vamos deixar

Mais essa história esquecida

Arauto:

História que muitas vezes O próprio povo não vê O próprio povo não crê Que ele poderia mudar Mesmo que os poetas Agindo como profetas Em versos venham alertar 
Poetas são visionários

Sabem dominar o tempo

E sempre previnem os homens

Mudando seu pensamento

Como o cordel que assistimos

Para vencer o tormento

E quando os poetas falam

Incomodam muita gente

Vereador, deputado

Homem de toda patente

Por isso são detestados

Pois a poesia não mente

(defuntos, com os instrumentos, se reúnem em fila, junto com Morte e Arauto)

Todos:

Uma incelença

Cantamos em respeito

A todos que se foram

E perderam seus direitos

Duas incelenças

Do fundo do peito

Nós pedimos paz

pelo mal que já foi feito

Três incelenças

Cantamos com amor

Adeus irmãos, adeus,

estamos a seu favor

(bumbo)

Alberto: No dia 2 de fevereiro, foi encontrado, próximo ao restaurante, o corpo do engenheiro Alberto Brumadinho.

Conceição: Conceição Brumadinho foi encontrada próximo ao corpo de Alberto.

Eustáquio: Os bombeiros encontraram também junto a eles o corpo de Eustáquio Brumadinho.

Arauto: Um fato, porém, surpreendeu a todos.
Defuntos: Os três corpos estavam de mãos dadas.

Arauto:
E assim os sonhos resistem
Com a força da esperança
Em cada flor que renasce
Em cada nova criança

Morte:

Em cada povo guerreiro

Que não se deixa abater

Lutando por seus direitos

E mostrando seu poder

Ciranda final:

\section{D G}

Eu só espero que não se repita

Outra tragédia igual

Não dá pra suportar

Eles vão ver que a força de um povo Quando junta e vibra

Ninguém vai parar

E Brumadinho não se entrega nunca Não vai ter empresa

Que possa barrar

Aguardaremos nova primavera

Uma nova era

Pra nos libertar!

André Luiz Freitas Dias é coordenador do Programa Transdisciplinar Polos de Cidadania da Faculdade de Direito da Universidade Federal de Minas Gerais (UFMG), professor e pesquisador do Departamento de Psicologia, do Programa de Pós-Graduação em Direito (mestrado e doutorado), do Programa de Pós-Graduação em Promoção de Saúde e Prevenção da Violência (mestrado profissional), da Faculdade de Medicina da UFMG e professor colaborador do Grupo Girche, da Universidade de Barcelona, Espanha.

Fernando Antônio de Mélo é coordenador do Programa Transdisciplinar Polos de Cidadania da Faculdade de Direito da UFMG, professor e pesquisador do Teatro Universitário da Universidade e dramaturgo e diretor geral da trupe "A torto e a direito". 